\title{
Implementation of a Blended-Learning Course as Part of Faculty Development
}

\author{
Daniel Tolks*, Iwona Pelczar*, Daniel Bauer, Thomas Brendel, Anja Görlitz, Julia Küfner, \\ Angelika Simonsohn, Inga Hege
}

Medical Education, Ludwig-Maximilians-University Munich, Munich, Germany

Email: inga.hege@med.uni-muenchen.de

Received 21 April 2014; revised 15 May 2014; accepted 5 June 2014

Copyright (C) 2014 by authors and Scientific Research Publishing Inc.

This work is licensed under the Creative Commons Attribution International License (CC BY). http://creativecommons.org/licenses/by/4.0/

c) (i) Open Access

\begin{abstract}
At the medical faculty at the Ludwig-Maximilians University in Munich many E-Learning resources are available to students, but they are rarely implemented in a Blended-Learning scenario. To foster this, a Blended-Learning course following the Inverted Classroom (IC) model as part of the faculty development curriculum has been developed. An initial 10-day E-Learning phase was based on the following six modules: E-Learning and Blended-Learning basics, Learning Management Systems, Virtual Patients, educational videos, the IC model and other E-Learning methods. In the following half-day face-to-face workshop the course participants applied their knowledge to common teaching scenarios. The course was well accepted by the participants and will be further developed and continued as part of the faculty development curriculum.
\end{abstract}

\section{Keywords}

Blended-Learning, Inverted Classroom, Flipped Classroom, Faculty Development, E-Learning

\section{Background}

Blended-Learning is an effective combination of E-Learning material and face-to-face teaching, such as lectures or seminars (Garrison \& Kanuka 2004). E-Learning means the use of electronic media and information and communication technologies for educational purposes. This includes numerous types of media such as text, audio, image, animation or video, and can be computer- or web-based learning (Kerres, 2013; Wikipedia).

One form of Blended-Learning is the Inverted Classroom (IC) or Flipped Classroom model. It was first described by Lage et al. in 2000, but only in recent years it was implemented in higher education. For example McLaughlin et al. describe the successful flipping of a pharmaceutics course (McLaughlin et al., 2014). The aim

\footnotetext{
"Equally contributed.
}

How to cite this paper: Tolks, D., Pelczar, I., Bauer, D., Brendel, T., Görlitz, A., Küfner, J., Simonsohn, A., \& Hege, I. (2014). Implementation of a Blended-Learning Course as Part of Faculty Development. Creative Education, 5, 948-953. 
of IC is a shift from passive learning during a face-to-face course to active learning fostering advanced skills such as analysis or synthesis.

An IC scenario starts with a self learning phase which is intended to teach factual knowledge preparing for the following face-to-face course. This is in contrast to traditional face-to-face courses such as lectures where students attend a course and afterwards complete the course topics at home.

The self-learning phase most often takes place online and provides materials such as videos, podcasts and quizzes. The material can be assembled either by integrating resources provided by experts (e.g. a video on YouTube) or by ones' own resources. For the latter approach there are no formal requirements, but typically the creation of the material can be done quickly and without great effort, e.g. by podcasting face-to-face courses or recording a presentation using a screencast program.

This approach saves time for the face-to-face course, which then can be used to focus on applying and deepening the previously acquired knowledge (Bergmann \& Sams 2012).

E-Learning has been an important component in the medical curriculum at the Ludwig-Maximilians-University (LMU) in Munich for many years. For example Virtual Patients (VPs) to teach clinical reasoning skills have been introduced successfully in the early 90s (Fischer et al., 1996). However, an integration of E-Learning resources in a Blended-Learning or even Inverted Classroom scenario, has not yet been implemented often. On the other hand many face-to-face courses, such as lectures are still taught in a traditional teacher-centered format.

To foster the integration of Blended-Learning and E-Learning scenarios into the medical curriculum a Blended-Learning course for lecturers was developed. The course concept basically followed the IC model and demonstrated to lecturers the possibilities and educational benefits of such scenarios.

\section{Methods}

\subsection{Course concept and implementation}

The Blended-Learning course has been developed at the Institut für Didaktik und Ausbildungsforschung in der Medizin at the medical faculty of the LMU. It was offered in November 2013 for the first time as part of the faculty development curriculum.

The course basically followed the IC model and consisted of two parts-a ten-day online course (self-learning phase) followed by a half-day face-to-face workshop to apply the knowledge taught in the online phase. The overall time needed to complete the course was calculated as seven hours (four hours self-study online, three hours face-to-face). Figure 1 shows the overall structure of the course including the topics covered in the online phase.

\subsection{Online Phase}

One week before the start of the online phase the participants received detailed information about the course objectives and activities and were able to get familiar with the learning management system (LMS) Moodle in which the course was implemented. They also were asked to briefly introduce themselves in the forum of the course. During the online phase a tutor was available to support the participants, who could post any questions or problems in the course forum.

The online course was divided into six modules (plus summary), which were available throughout the ten-day period and could be freely navigated and repeated. The modules and the provided materials are described in detail in Table 1.

All modules provided further reading material and important terms were explained in a course glossary.

The video lectures were captured and streamed with LMUCast, an easy video software to be used; educational videos were studio-like recorded and edited with Final Cut Pro. The online course was open-ended so participants could revisit the course any time after the course ended.
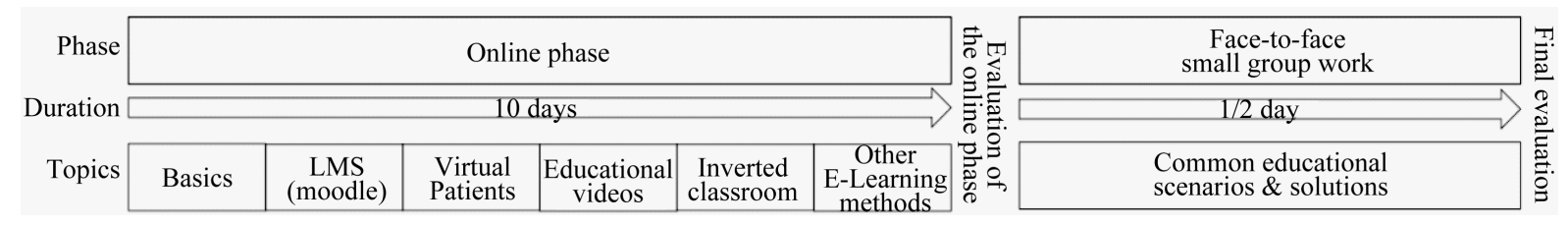

Figure 1. Overall course structure and topics. 
Table 1. Structure of the online course modules.

\begin{tabular}{|c|c|c|c|}
\hline Module & $\begin{array}{l}\text { Approx. } \\
\text { Duration (min) }\end{array}$ & Topics & Material \\
\hline Introduction \& Basics & 45 & $\begin{array}{ll}\text { - } & \text { Course overview and Introduction } \\
\text { - } & \text { Basics: } \\
\text { - } & \text { E-Learning } \\
\text { - } & \text { Blended-Learning } \\
\text { - } & \text { Learning objectives and competencies }\end{array}$ & $\begin{array}{ll}\text { - } & \text { Four Video-Lectures } \\
\text { - } & \text { Three quizzes (11 questions) }\end{array}$ \\
\hline LMS (Moodle) & 30 & - Implementation strategies and examples & $\begin{array}{l}\text { - } \quad \text { Two Video-Lectures } \\
\text { - } \quad \text { Two quizzes (10 questions) }\end{array}$ \\
\hline Virtual Patients (VPs) & 30 & $\begin{array}{l}\text { - } \quad \text { Basics about VPs } \\
\text { - } \quad \text { Integration into curriculum }\end{array}$ & $\begin{array}{l}\text { - } \quad \text { Two Video-Lectures } \\
\text { - } \quad \text { Two Quizzes (five questions) }\end{array}$ \\
\hline Educational videos & 50 & - Planning and implementing educational videos & $\begin{array}{ll}\text { - } & \text { One Video-Lecture } \\
\text { - } & \text { Three Educational videos } \\
\text { - } & \text { Three Quizzes (14 questions) }\end{array}$ \\
\hline Inverted Classroom & 60 & $\begin{array}{ll}\text { - } & \text { Basics } \\
\text { - } & \text { Implementation strategies for Inverted Classrooms }\end{array}$ & $\begin{array}{ll}\text { - } & \text { One Video-Lecture (Introduction) } \\
\text { - } & 5 \text { Open Educational videos } \\
\text { - } & \text { Two Quizzes (five questions) } \\
\text { - } & \text { Tutorial \& Summary }\end{array}$ \\
\hline $\begin{array}{l}\text { Other E-learning } \\
\text { methods }\end{array}$ & 10 & $\begin{array}{l}\text { - Introduction of E-Portfolio, Serious Games, } \\
\text { Flashcards, Audience Response Systems. }\end{array}$ & $\begin{array}{ll}\text { - } & \text { Tutorial } \\
\text { - } & \text { Quiz (one question) }\end{array}$ \\
\hline Summary & 25 & $\begin{array}{l}\text { - Information and preparation of face-to-face workshop } \\
\text { - Evaluation }\end{array}$ & - Evaluation form \\
\hline
\end{tabular}

\subsection{Workshop}

During the half-day (3 hours) face-to-face workshop participants worked in small groups coached by a tutor and applied their knowledge to previously chosen scenarios.

Each scenario described a common problem, e.g. heterogeneous knowledge of students attending a seminar. A framework was provided to assist the participants in working through the scenario. For example, it contained questions such as "which competencies are addressed in the described scenario?" or "which is the problem in the described scenario?”.

The participants discussed possible answers to the problem applying an E-Learning or Blended-Learning approach and presented their solution to the group. The proposals were discussed by the participants and tutors. Finally there was a feedback round.

\subsection{Evaluation}

Following the online phase the participants were asked to anonymously complete a 43-item online questionnaire. The questions on a Likert scale $(1=$ totally agree, 5 totally disagree $)$ and school grades $(1=$ very good, $2=$ good, $3=$ satisfactory $4=$ sufficient, 5 = bad $6=$ very bad) were related to the provided modules, didactical and technical aspects as well as self-estimation of knowledge.

Moreover participants could enter comments about what they liked and what could be improved.

After the workshop participants completed a similar paper-based 36-item questionnaire regarding the overall course as well as structure, support and topics of the workshop.

The anonymous log data of Moodle were analyzed to investigate the usage pattern of the course participants. All data were analyzed using Microsoft Excel.

\section{Results}

\subsection{Course Concept and Implementation}

Eight lecturers enrolled for the course; seven (male: 5, female: 2) actively participated in the online part and six (male: 4, female: 2) attended the half-day workshop in November 2013. The effort for supporting the online part included sending information and reminders through the forum, answering questions and preparing the groups for the workshop according to the preferences of the participants. 


\subsection{Online phase}

The summarized evaluation results of the online phase can be seen in Table 2. During the ten-day course the tutor was contacted twice for minor technical issues, which were solved immediately.

Analysis of the log data showed that six participants completed all provided material, one participant accessed the course, but did not work through the material.

Five of these six active participants worked through the course towards the end of the 10-day time-span. One participant worked through the course material regularly during the 10 days.

\subsection{Workshop}

During the workshop two small groups with three participants each worked on a scenario and applied the methods taught in the online course. The chosen scenarios were:

1) A lecturer of a 90-minutes seminar realizes that he does not have enough time to teach all relevant content.

2) In a bedside-teaching course a lecturer realizes that his students have good theoretical knowledge but have a substantial lack of differential diagnostic reasoning skills.

For each small group a tutor was available to answer any questions.

\subsection{Final Evaluation}

The final questionnaire was completed by six participants. A summary of the results is shown in Table 3 .

Most of the comments of the participants were positive and emphasized that they especially liked the part about the IC model, e.g. "[I liked] that in the inverted classroom part experts in this area were involved".

The integrated quizzes were also rated as positive, however, criticism was voiced that some were too easy.

Table 2. Summarized evaluation data of the online course $(n=6)$.

\begin{tabular}{lc}
\hline Module & Average Rating (school grades, $1=$ very good, $6=$ very bad) \\
\hline E-Learning \& Blended-Learning basics & 1.3 \\
LMS (Moodle) & 1.8 \\
Virtual Patients & 1.7 \\
Educational videos & 1.8 \\
Inverted Classroom & 3.0 \\
Other E-learning methods & Average Rating (1 = totally agree, 5= totally disagree) \\
Overall rating & 1.7 \\
\hline Question & 1.7 \\
Using the learning management system was easy. & 1.5 \\
I could answer the questions on the basis of the provided material. & \\
\hline
\end{tabular}

Table 3. Summary of the results of the evaluation of the online course and the workshop $(n=6)$.

\begin{tabular}{|c|c|}
\hline Question & $\begin{array}{c}\text { Average rating ( } 1 \text { = totally agree, } \\
5=\text { totally disagree })\end{array}$ \\
\hline A course about E-learning \& Blended-Learning in medicine makes sense. & 1.0 \\
\hline The learning objectives of the course were clearly stated. & 2.2 \\
\hline The content was comprehensible. & 1.5 \\
\hline The required amount of time to complete the course was in accordance with my expectations. & 1.8 \\
\hline The scenarios for the workshop were adequate to apply my knowledge. & 1.2 \\
\hline The online course was a good preparation for the workshop. & 1.3 \\
\hline The splitting of the course in two parts (online and face-to-face) was successful. & 1.2 \\
\hline I feel comfortable integrating E-learning into my teaching activities & 1.7 \\
\hline
\end{tabular}




\section{Discussion}

The evaluation results suggest that the course concept was well accepted by the lecturers. They appreciated especially the Blended-Learning concept consisting of the two parts.

\subsection{Online Phase}

The implementation of the modules followed different approaches appropriate to the delivered content. For example the educational video module delivered the knowledge through comprehensive videos and the inverted classroom module combined external open resources provided by experts with basic captured screen casts. The online modules were on average rated with 1.7, only the presentation of the other E-learning methods was less favored. An explanation could be that this was the only module that did not provide any videos, but only textbased information.

Surprisingly the Inverted Classroom module was well accepted by the participants (average rating 1.5); they even emphasized this in their comments and especially liked that (external) expert interviews were provided in this module. This is an indicator that the participants were willing to get involved with a new teaching method.

However, due to the small number of participants we did not further analyze the evaluation data and more data is needed to confirm these initial results.

Most of the participants did not work regularly during the 10 days, but completed all E-learning resources toward the end of the online phase. This usage pattern is also typical for undergraduate medical students. For this target group a spaced activation of the E-learning resources (two virtual patients/week) led to a more balanced usage pattern (Maier, Hege, Muntau, Huber, \& Fischer 2013). A review by Roher et al. concluded that such a spacing effect can improve long-term knowledge retention (Roher \& Pashler 2010); accordingly the course concept is currently adapted to a two to three week duration with a sequential activation of the six modules.

\subsection{Workshop}

Overall the workshop was well accepted by the participants.

At the end of the workshop participants were enthusiastic and requested that the course material should be available even though the course had ended. They were also strongly encouraged by the course instructors to stay in contact and ask for support when planning to implement a Blended-Learning course. However, since the end of the course, none of them re-visted the course or contacted the instructors. Reason for this could be the workload of the participants who have to fulfill clinical, teaching and research duties. But there also might be a lack of practical relevance, since the scenarios represent common problems in higher education, but might not reflect the particular challenge on which the lecturer is focused. Therefore we plan to further develop the course to encourage participants to bring in their own scenarios. Moreover a post-phase will be included to which the participants will be explicitly invited and supported in implementing their own Blended-Learning course into their curriculum.

\section{Outlook}

The overall Blended-Learning course concept has proven to be successful and well accepted in this first implementation. Therefore the course will be offered twice a year for a maximum of 12 participants per course as an integral part of the faculty development curriculum.

Based on future evaluation results and usage patterns the course will also be further developed and improved. Ideas include the introduction of a post-course phase in which the participants will be asked and supported in implementing and integrating their own Blended-Learning concepts. Beginning with the next course in spring 2014 we will implement a follow-up strategy to support and motivate participants to apply what they have learned to their curriculum.

\section{Acknowledgements}

The authors want to thank the course participants for their helpful feedback.

For the realization of the workshop the authors especially thank B. Nechansky, P. Christ from the faculty development team of the medical faculty at LMU for their support before, during and after the workshop. 
For the implementation of the online phase in cooperation with the authors T. Bischoff, B. Aulinger and G. Brauer contributed to the planning and implementation of the course.

Finally the authors want to thank Prof. Hal Lyon for critically reviewing the manuscript focusing also on language and grammar.

\section{References}

Bergmann, J., \& Sams, A. (2012). Flip Your Classroom: Reach Every Student in Every Class Every Day. Eugene, OR: International Society for Technology in Education.

Fischer, M., Schauer, S., Gräsel, C., Baehring, T., Mandl, H., Gärtner, R., Scherbaum, W., \& Scriba, P. (1996). CASUS Model Trial. A Computer-Assisted Author System for Problem-Oriented Learning in Medicine. Zeitschrift für Aerztliche Fortbildung (Jena), 90, 385-389.

Garrison, D. R., \& Kanuka, H. (2004). Blended Learning: Uncovering Its Transformative Potential in Higher Education. The Internet and Higher Education, 7, 95-105. http://dx.doi.org/10.1016/j.iheduc.2004.02.001

Kerres, M. (2013). Mediendidaktik. Konzeption und Entwicklung mediengestützter Lernangebote (4th ed.). München: Oldenbourg Verlag. http://dx.doi.org/10.1524/9783486736038

Lage, M. J., Platt, G. J., \& Treglia, M. (2000). Inverting the Classroom: A Gateway to Creating an Inclusive Learning Environment. The Journal of Economic Education, 31, 30-43. http://dx.doi.org/10.2307/1183338

LMUCast. https://cast.itunes.uni-muenchen.de/

Maier, E., Hege, I., Muntau, A. C., Huber, J., \& Fischer, M. R. (2013). What Are Effects of a Spaced Activation of Virtual Patients in a Pediatric Course? BMC Medical Education, 13, 45, http://dx.doi.org/10.1186/1472-6920-13-45

McLaughlin, J. E., Roth, M. T., Glatt, D. M., Gharkholonarehe, N., Davidson, C. A., Griffin, L. M., Esserman, D. A., \& Mumper, R. J. (2014). The Flipped Classroom: A Course Redesign to Foster Learning and Engagement in a Health Professions School. Academic Medicine, 89, 236-243, http://dx.doi.org/10.1097/ACM.0000000000000086

Moodle. https://moodle.org

Roher, D., \& Pashler, H. (2010). Recent Reserach on Human Learning Challenges Conventional Instructional Strategies. Educational Researcher, 39, 406-412. http://dx.doi.org/10.3102/0013189X10374770

Wikipedia. http://en.wikipedia.org/wiki/E-learning 
Scientific Research Publishing (SCIRP) is one of the largest Open Access journal publishers. It is currently publishing more than 200 open access, online, peer-reviewed journals covering a wide range of academic disciplines. SCIRP serves the worldwide academic communities and contributes to the progress and application of science with its publication.

Other selected journals from SCIRP are listed as below. Submit your manuscript to us via either submit@scirp.org or Online Submission Portal.
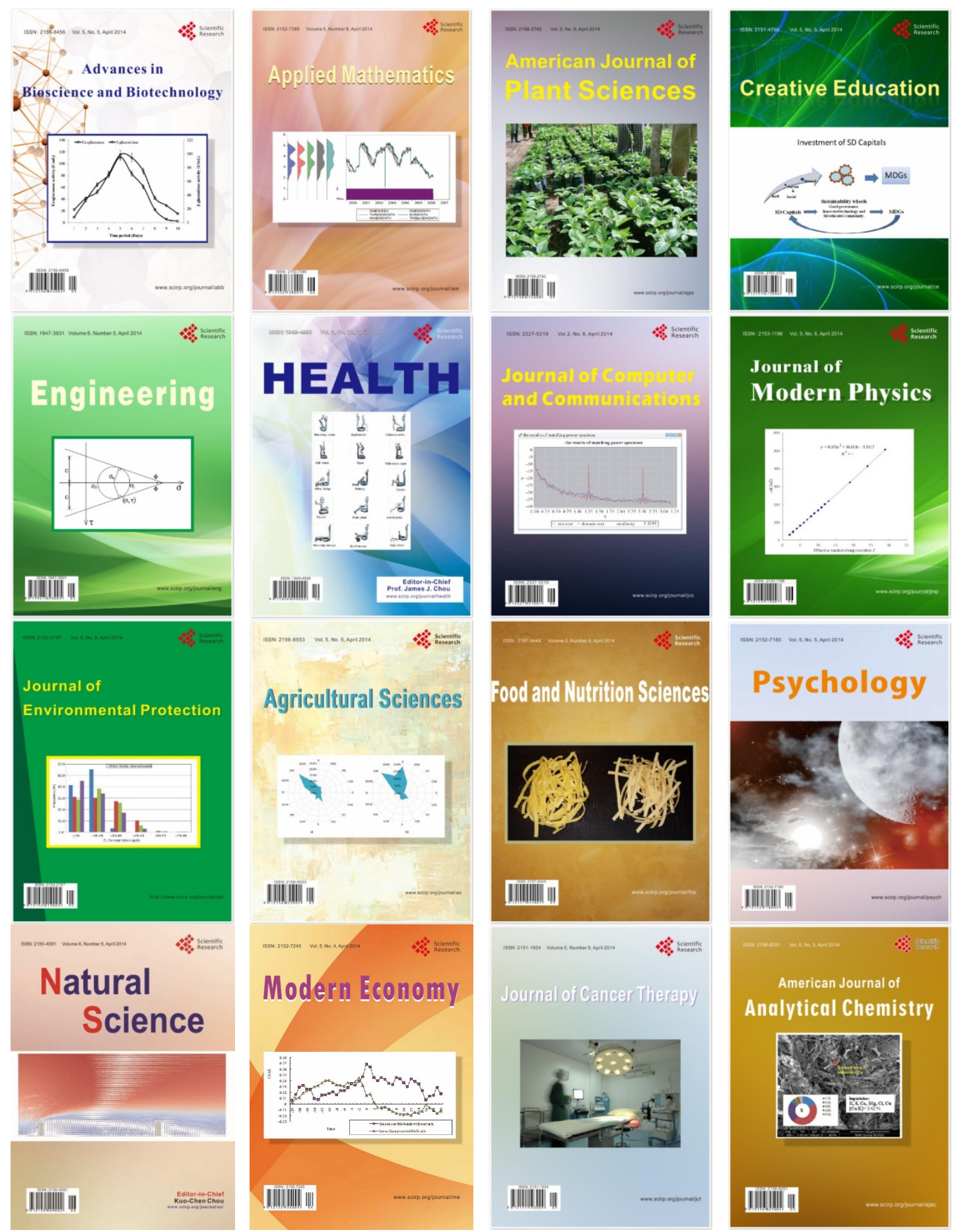